\title{
A corpus-based approach to tense and aspect in English-Chinese translation
}

\author{
Zhonghua Xiao and Tony McEnery
}

Lancaster University

English is predominantly a tense language, whereas Chinese is exclusively an aspect language (c.f. Wang, 1943:151; Gao, 1948:189; Gong, 1991:252; Norman, 1988:163). While tense and aspect both provide temporal information, they are two different concepts. Tense is deictic in that it indicates the temporal location of a situation, i.e., its occurrence in relation to a specific reference time $^{1}$. Aspect is non-deictic in that it is related to the temporal shape of a situation, i.e., its internal temporal structure and ways of presentation, independent of its temporal location. As such, Chinese does not have the grammatical category of tense, because the concept denoted by tense is indicated by content words like adverbs of time or it is implied by context ${ }^{2}$. Aspectual meanings, however, are signaled by aspect markers, grammaticalised function words that convey aspectual meaning. In short, Chinese grammatically marks aspect but does not grammatically mark tense. English, however, grammatically marks both tense and aspect. Even though both languages mark aspect, the aspect system in these two languages differs significantly. In this paper, we will explore these differences using an English-Chinese parallel corpus, showing how aspectual meanings and temporal notions in English texts are translated into Chinese.

This paper consists of 7 parts. Section 1 makes a brief introduction to aspect in English and Chinese; section 2 presents the corpus data used in this paper; section 3 discusses the translation patterns of the English progressive, section 4 explores the translation patterns of the English perfect; section 5 discusses the perfect progressive; section 6 is concerned with the simple aspect in English and section 7 concludes the paper.

\footnotetext{
${ }^{1}$ In a tense language, tense and grammatical aspect are often combined morphologically. In English, for example, the simple past not only presents a situation as perfective, but also locates it prior to the speech time; similarly, the French imparfait is both past and perfective. However, grammatical aspect and tense can also be encoded distinctly, as demonstrated in Polish (Weist et al, 1984).

${ }^{2}$ In Chinese, like in many SE Asian languages (Baker, 2002), temporal placement of a situation is shown predominantly by contexts. When a specific time reference is needed nut not available through context, temporal adverbials are generally used.
} 


\section{Aspect in Chinese and English}

The research presented in this paper was conducted within the framework of Smith's (1997) two-component aspect theory, according to which the aspectual meaning of a sentence is the synthetic result of the two components of aspect, namely, situation aspect and viewpoint aspect. The former refers to the internal temporal structure of an idealized situation while the latter is concerned with different presentations of that internal temporal structure. There are six attested situation types, the temporal features of which are summarized in Table 1:

Table 1: Feature matrix system of attested situation types:

\begin{tabular}{lccccc}
\hline Classes & {$[ \pm$ dynamic $]$} & {$[ \pm$ durative $]$} & {$[ \pm$ bounded] } & {$[ \pm$ telic] } & {$[ \pm$ result $]$} \\
\hline ACT & + & + & - & - & - \\
SEM & + & - & \pm & - & - \\
ACC & + & + & + & + & - \\
ACH & + & - & + & + & + \\
ILS & - & + & - & - & - \\
SLS & \pm & + & - & - & - \\
\hline Legend: & ILS=individual-level state & SLS=state-level state & ACT=activity \\
& SEM=semelfactive & & ACC=accomplishment & ACH=achievement
\end{tabular}

While situation aspect shows striking similarities cross-linguistically, viewpoint aspect is language specific (c.f. Bybee, Perkins and Pagliuca, 1994; Smith, 1997; Zhang, 1995). Chinese as an aspect language has an almost complete set of markers to express different temporal perspectives. The basic viewpoint distinction in Chinese is drawn between perfective and imperfective, as in many other languages (c.f. Dahl, 1985). In Chinese, there are four simplex perfective viewpoints actual -le, experiential -guo, delimitative verb reduplication, completive resultative verb complements (RVCs) — and four simplex imperfective viewpoints — durative -zhe, progressive zai, inceptive -qilai, and successive -xiaqu — in addition to a couple of complex viewpoints. Aspectual meanings in Chinese can be realised in three ways: (i) marked explicitly by aspect markers, for example -le, (ii) marked adverbially, for example zheng, and (iii) marked covertly, i.e., taking the lack-viewpoint-morpheme (LVM) form. While Chinese is rich in aspect markers, it is interesting to note that covert marking of the LVM form is a frequent and important strategy to express aspectual meanings in Chinese discourse (c.f. McEnery and Xiao, 2002). In contrast, 
English is a less aspectual language with regard to viewpoint aspect. English only differentiates between the simplex viewpoints of the progressive, the perfect and the simple aspect in addition to the complex viewpoint of the perfect progressive (c.f. Biber, Johansson, Leech \& Finegan, 1999: 461; Svalberg \& Chuchu, 1998).

While English and Chinese both have a progressive viewpoint, it is used differently in the two languages (c.f. section 3). Chinese does not have the perfect, yet English does. Also the English simple aspect does not correspond to the perfective viewpoints in Chinese. In the sections that follow, we will first present our corpus data (section 2), based on which the translation patterns of English aspect and the effects of situation aspect on these patterns will be explored (sections 3-5).

\section{The English-Chinese parallel corpus}

Corpora as a source for linguistic research have "always been pre-eminently suited for comparative studies” (Aarts, 1998). The convergence of the corpus methodology and contrastive studies to form "corpus-based contrastive study" (Santos, 1995) or "contrastive corpus linguistics" (Aijmer \& Altenberg, 1996:12) seems quite natural. This has in part been facilitated by the design decisions made when constructing monolingual corpora. For instance, the British National Corpus (BNC), the Korean National Corpus (Park, 2001) and the Chinese National Corpus (Zhou and Yu, 1997) have adopted a quite similar sampling frame and thus made contrastive studies of these languages possible. The design of multilingual and parallel corpora is even more explicitly driven by the wish to conduct linguistic contrast (c.f. Johnson \& Hofland, 1994:25-37; Aarts, 1998).

In this paper we are concerned with Chinese expressions of translated aspectual meanings from English, hence we are using a unidirectional parallel corpus for our study where English is the source language and Chinese is the target language. The corpus is composed of bilingual texts taken from English World, a web-based journal published in China ${ }^{3}$. The sampling period is between October 2000 and February 2001, during which 100,170 English words and their

\footnotetext{
${ }^{3}$ The URL of the web-based journal is http://www.bentium.net. We are grateful to Dr. Junfeng Hu of Institute of Computational Linguistics, Beijing University for allowing us to access his materials. Thanks are also due to the editors and translators of these texts.
} 
translation in the form of 192,088 Chinese characters were gathered. Our corpus is relatively small as we are interested in a frequent grammatical feature, where the syntactic freezing point is fairly low ${ }^{4}$ (c.f. Biber, 1988; Givon, 1995).

The English component of the parallel corpus was POS tagged automatically using the CLAWS tagger which applied the BNC C7 tagset. CLAWS (Constituent-Likelihood Automatic Word Tagging System) is an automatic POS tagger for English developed at Lancaster University. The system employs a probabilistic Hidden Markov Model and is enhanced by pattern matching rules (Garside, 1990; Garside \& Smith, 1997). This tagger is reported to have achieved an accuracy rate of 97\% on general written English (c.f. Garside and Smith, 1997). The Chinese component of the corpus was tokenized and POS tagged using the CKIP Segmenter, which is reported to have achieved a tagging precision rate of 95\% (c.f. Gao, 1997). The automated part-of-speech analysis in both English and Chinese components was hand corrected prior to the corpus being used. This means that the parallel corpus used in this paper is generally reliable.

Figure 4: A Snapshot of the parallel corpus:

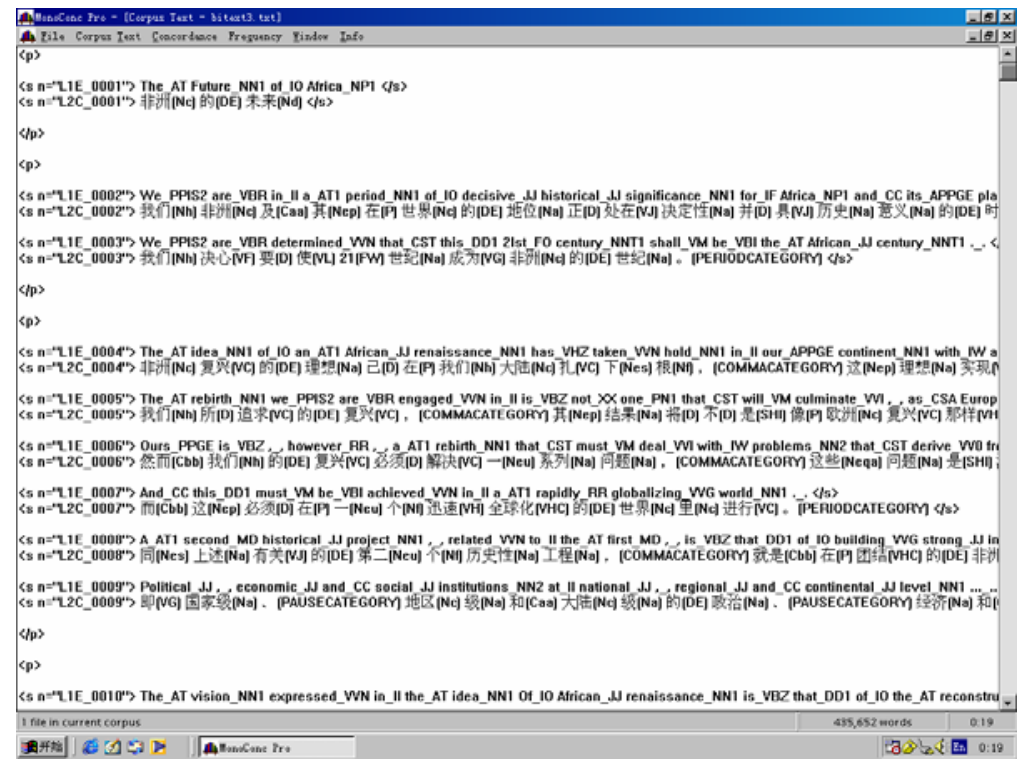

In order to make the study easier, the parallel corpus was aligned at the sentence level. The

\footnotetext{
${ }^{4}$ Hakulinen et al (1980:104) claim that "the sample size above which you cannot really find significant changes in the parameters and their frequencies is a corpus of a few hundred sentences” (quoted from Santos, 1996:11)
} 
alignment was initially undertaken using Piao's (2000) sentence alignment program. The output from this program was then corrected by hand to ensure accurate alignment. The aligned corpus contains 6,101 translation pairs. For ease of reference, each sentence in the corpus is preceded by a unique sentence identifier. For example, $<\mathrm{s} n=$ "L1E_6001" $>$ indicates that this is sentence No. 6001 of the English source data, while $<\mathrm{s}$ n= "L2C_0010" $>$ refers to the $10^{\text {th }}$ sentence of the target language of Chinese. Figure 4 above is a snapshot of the corpus.

The English texts of the parallel corpus contains 7,716 tensed verbs ${ }^{5}$, as shown in Table 3 below:

Table 3: Tensed verbs in the English texts:

\begin{tabular}{|l|l|l|l|l|l|}
\hline Aspect & Present & Past & Future & Total & Percent \\
\hline Progressive & 164 & 110 & 3 & 277 & $3.61 \%$ \\
\hline Perfect & 371 & 253 & 3 & 627 & $8.17 \%$ \\
\hline Perf. prog. & 16 & 8 & 0 & 24 & $0.31 \%$ \\
\hline Simple & 3,037 & 3,468 & 242 & 6,747 & $87.91 \%$ \\
\hline Total & 3,588 & 3,839 & 248 & 7,675 & $100 \%$ \\
\hline
\end{tabular}

As can be seen from the table, the majority of the tensed verbs take the simple aspect. The perfect is less frequent than the simple aspect but more common than the progressive. The perfect progressive occurs only rarely. These findings are in line with those reported in Biber, Johansson, Leech \& Finegan (1999: 461) ${ }^{6}$.

\section{The progressive aspect}

In addition to its canonical use to signal the ongoing nature of a situation, "the progressive in English has a number of other specific uses that do not seem to fit under the general definition of progressiveness" (Comrie, 1976:37). These "specific uses" include its use to indicate habitual or iterative situations, to indicate anticipated happenings in the future, and some idiomatic use to add greater emotive effect (c.f. Leech, 1971; Comrie, 1976).

\footnotetext{
${ }^{5}$ In English, verbs in finite clauses are marked for either tense or modality, but not for both (Biber, Johansson, Leech \& Finegan (1999: 253). Note, however, while will, shall and be going to are treated as modal verbs in Biber et al (ibid: 456), they are considered as markers for simple future in this paper, as in many instances, futurity and modality are hardly distinguishable (c.f. Comrie, 1985: 21).

${ }^{6}$ The counts in the table do not include copular verb be. That explains the proportion of simple aspect in our data is slightly lower than 90\%, the proportion reported in Biber, Johansson, Leech \& Finegan, 1999: 461).
} 
In Chinese, however, the progressive marked by zai ${ }^{7}$ only corresponds to the first category above, namely, to mark the ongoing nature of dynamic situations. Apart from the progressive zai, a related but distinct viewpoint is the durative aspect marked by -zhe, which signals the durative and continuous feature of either dynamic or stative situations. In addition, the adverb zheng "just, exactly" also indicates the ongoing nature of a situation when modifying a predicate ${ }^{8}$.

In the English component of our parallel corpus, a total of 277 instances of simplex progressives were found ${ }^{9}$, as shown in Table 4 below:

Table 4: Distribution of progressives in the English source data:

\begin{tabular}{|l|l|}
\hline Use & Frequency \\
\hline Ongoing situations & 259 \\
\hline Habitual situations & 6 \\
\hline Anticipated happenings & 12 \\
\hline Total & 277 \\
\hline
\end{tabular}

These progressives are translated into Chinese either as ongoing (58.12\%), or as perfective (40.79\%), or paraphrased/omitted (1.09\%). The aspectual meanings can be marked either overtly or covertly, i.e., by taking the lack-viewpoint-morpheme (LVM) form, as shown in Table 5 below. This table is revealing. First, in English-Chinese translation, most progressives in English (58.12\%) do not undergo viewpoint aspect shift, though some of them (15.52\%) may take the LVM form. Second, whether a viewpoint aspect shift occurs in translation depends largely on the specific use of the progressive in the English source data, and on the interaction between situation aspect and viewpoint aspect in the Chinese target language. This means that on the one hand, when progressives in the English source data that indicate habitual situations or anticipated happenings are translated into Chinese, they necessarily undergo a viewpoint aspect shift, because the

\footnotetext{
${ }^{7}$ Apart from signalling progressiveness (e.g., ta zai kanshu "He is reading”), zai can also function as a locative preposition (e.g., ta zai tushuguan "He is in the library”), or play the dual role (e.g., ta zai tushuguan kanshu "He is reading in the library”). Anyway, progressiveness means localising a situation (c.f. Xiao, 2002). In this paper, the progressive zai refers to either the marker zai or the dual zai.

${ }^{8}$ Zheng is not considered as a fully-fledged aspect marker because it is only related to progressiveness when in combination with a predicate while it is possible for it to modify almost all parts of speech.

${ }^{9}$ The count does not include the complex viewpoint of prefect progressive, which will be discussed in section 5 .
} 
progressive in Chinese does not indicate habituality or futurity. On the other hand, when a translation triggers a situation type shift into individual-level state (ILS) or achievement (ACH) in the Chinese target language, a viewpoint aspect shift is expected, because these two types of situations do not normally take the prototypical progressive ${ }^{10}$ (c.f. Smith, 1997).

Table 5: Aspect marking of English progressive in Chinese translations:

\begin{tabular}{|c|c|c|c|c|}
\hline [ \pm Progresssive] & Aspect marker & Situations & Frequency & Total \\
\hline \multirow{17}{*}{ Progressive } & \multirow{3}{*}{ (zheng)zai } & SLS & 1 & \multirow{13}{*}{$\begin{array}{l}118 \\
(42.6 \%)\end{array}$} \\
\hline & & ACT & 50 & \\
\hline & & ACC & 7 & \\
\hline & \multirow{3}{*}{-zhe } & ILS & 3 & \\
\hline & & SLS & 2 & \\
\hline & & ACT & 6 & \\
\hline & (zheng)zai...-zhe & ACT & 7 & \\
\hline & \multirow[t]{2}{*}{ dual zai } & ACT & 8 & \\
\hline & & ACC & 1 & \\
\hline & \multirow{4}{*}{ zheng } & ILS & 1 & \\
\hline & & ACT & 22 & \\
\hline & & ACC & 4 & \\
\hline & & $\mathrm{ACH}$ & 6 & \\
\hline & \multirow{4}{*}{ LVM } & SLS & 1 & \multirow{4}{*}{$\begin{array}{l}43 \\
(15.52 \%)\end{array}$} \\
\hline & & ACT & 37 & \\
\hline & & ACC & 4 & \\
\hline & & $\mathrm{ACH}$ & 1 & \\
\hline \multirow{10}{*}{$\begin{array}{l}\text { Non- } \\
\text { progressive }\end{array}$} & \multirow{3}{*}{-le/meiyou } & ACT & 2 & \multirow{5}{*}{$\begin{array}{l}30 \\
(10.83 \%)\end{array}$} \\
\hline & & ACC & 1 & \\
\hline & & $\mathrm{ACH}$ & 4 & \\
\hline & RVC & $\mathrm{ACH}$ & 17 & \\
\hline & RVC...-le & $\mathrm{ACH}$ & 6 & \\
\hline & \multirow{5}{*}{ LVM } & ILS & 49 & \multirow{5}{*}{$\begin{array}{l}83 \\
(29.96 \%)\end{array}$} \\
\hline & & SLS & 1 & \\
\hline & & ACT & 17 & \\
\hline & & ACC & 4 & \\
\hline & & $\mathrm{ACH}$ & 12 & \\
\hline \multicolumn{3}{|c|}{ Paraphrase/omission } & 3 & $3(1.09 \%)$ \\
\hline & & Total & & 277 (100\%) \\
\hline
\end{tabular}

It is also interesting to note that when a telic situation (accomplishment or achievement) is

\footnotetext{
${ }^{10}$ In the corpus, we do find 4 individual-level states taking -zhe or zheng, and 1 achievement taking zheng (note that achievement is strictly incompatible with the durative -zhe), none of these situation types take the progressive zai.
} 
translated into Chinese, it is more likely (65.67\%) to be presented perfectively, because only a perfective viewpoint covers its final spatial endpoint. Activities, however, rarely undergo viewpoint aspect shifts. Of the 149 activities taking the progressive form in English, only 19 are translated prefectively. A closer examination of the concordances of these sentence pairs tells the full story, as shown in Table 6 below.

Table 6: Translation of activities:

\begin{tabular}{|c|c|c|}
\hline Uses & Aspect marking & Frequency \\
\hline Anticipated happenings & \multirow{4}{*}{ LVM } & 4 \\
\hline Habitual situations & & 6 \\
\hline Future progressive & & 5 \\
\hline Reporting verbs (e.g. say, shout) & & 2 \\
\hline Others & -le & 2 \\
\hline & Total & 19 \\
\hline
\end{tabular}

As noted earlier in this section, when an English progressive is indicating a meaning other than canonical progressiveness, it is quite natural to expect a viewpoint aspect shift. Verbs introducing direct speech, such as shuodao "say", handao "shout”, xiaodao "laugh", are normally incompatible with imperfective viewpoints when they function as reporting verbs. Hence these verbs are naturally translated perfectively. Yet viewpoint aspect is subjective, and the speaker, as well as the translator, can choose to present an activity perfectively or imperfectively provided that no conflict arises between situation aspect and viewpoint aspect. As such, the same activity may be presented imperfectively in the English source data (e.g., <s n="L1E_5086"> As if the machine was somehow drawing power from the people that were around it), whereas it is translated perfectively into Chinese (e.g., <s n="L2C_5086"> 那架机器似乎是从围观 的人身上 获取了力量 “that-CL machine as-if SHI from on-looking GEN people body acquire-le power” $)^{11}$. It is also possible to present the situation as ongoing (e.g., 那架机器似乎是在 从围观的人身上 获取 力量 “that-CL machine as-if SHI PROG from on-looking GEN people body acquire power"). Viewpoint aspect allows the speaker to focus on a part or the whole

\footnotetext{
${ }^{11}$ A similar example found in the corpus is <s n="L1E_3636"> ("Valuable time is now being wasted waiting to get funds," says Mr. Shapshanov.) vs. <s n="L2C_3636"> (沙普沙诺夫 先生 说 : “宝贵的时间在 等待贷 款 中白白 地浪费了。”)
} 
of a situation. But when the translator chooses to present an activity in its entirety, the perfectivity needs to be marked explicitly.

In English, when the progressive aspect combines with tense, the past progressive, present progressive and future progressive result. As Chinese does not have the grammatical category of tense, the temporal notions indicated by English tenses are lexicalized in Chinese. This means that while the past and present progressives in the English source data follow the patterns identified above when they are translated into Chinese, the future progressive (i.e., will/would/be going to + be + V-ing), which signals the ongoing nature of a situation with a future time reference ${ }^{12}$ in the English source data, is always translated perfectively, though adverbs and modal auxiliaries like jiang "will”, jijiang "soon”, yao "shall, will”, and hui "be likely/sure to" are often used to mark futurity.

\section{The perfect aspect}

The perfect aspect is not monolithic. There are sub-categorizations of perfectivity that are possible. According to Comrie (1976: 56), the current relevance of a situation in the past can be manifested in four different ways: the perfect of result, the perfect of experience, the perfect of persistent situation, and the perfect of recent past. It is this four-way split of the perfect that will be used in this section. However, before applying this categorization to the data it is useful to consider the perfect in English and Chinese. The English perfect as a viewpoint aspect is different from other aspects in that it relates a previous situation to the present. Chinese does not have perfect constructions. While the change-of-state (COS) le does denote current relevance state (CRS), it is not restricted to the present. Rather the COS le can indicate the current relevance relative to a past, present, or future time reference. When a sentence takes both the actual -le and the COS le, it is translatable by the English perfect (c.f. also Henne et al, 1977:113), because the COS le in combination with the actual -le denotes a previous situation continuing into the present.

\footnotetext{
${ }^{12}$ This is not the only use of the future progressive, though, as Leech (1987) observes, in everyday speech the future progressive "is often a more polite and tactful alternative to the non-progressive form."
} 
As Comrie (1976: 53) notes, not every form labeled "perfect" expresses perfect meaning. The nonfinite verb constructions with having plus past participle, for instance, indicate relative anteriority, because "in such constructions, the distinction between perfect meaning and relative past time reference is not made overtly (is neutralized)" (Comrie, 1976: 55). Perfect forms taking modals such as must, would, could, and may/might do not denote perfect meaning either ${ }^{13}$ (c.f. also Brinton, 1988: 248). Comrie (1976; 1985) even argues that the past perfect (pluperfect) and the future perfect are absolute-relative tenses rather than aspect and outlines their differences from the perfect. While Comrie's (ibid) argument does hold some water, it is undeniable that the pluperfect and the future perfect can indeed indicate perfect meanings. The most obvious case is indirect speech, where the perfect is rewritten as the pluperfect when the main clauses are in the past tense. Even in narratives, not all instances signal relative anteriority alone. As such, we will consider the present perfect as the perfect in its real sense, while the pluperfect and the future perfect are treated as a special case of the perfect (see discussions later in this section). There are 371 instances of the perfect in our parallel corpus ${ }^{14}$. The perfect of result is the most common of the four types of perfect, as shown in Table 7:

Table 7: The perfect in the parallel corpus:

\begin{tabular}{|c|c|c|c|}
\hline Type of perfect & Situation type & Frequency & Percent \\
\hline \multirow[t]{2}{*}{ Perfect of result } & Accomplishments & 56 & \multirow[t]{2}{*}{$59.03 \%$} \\
\hline & Achievements & 163 & \\
\hline \multirow{5}{*}{ Experiential perfect } & ILS & 1 & \multirow{5}{*}{$12.13 \%$} \\
\hline & SLS & 1 & \\
\hline & Activities & 16 & \\
\hline & Accomplishments & 10 & \\
\hline & Achievements & 17 & \\
\hline \multirow{3}{*}{$\begin{array}{l}\text { Perfect of persistent } \\
\text { Situation }\end{array}$} & ILS & 59 & \multirow{3}{*}{$26.41 \%$} \\
\hline & SLS & 1 & \\
\hline & Activities & 38 & \\
\hline \multirow{3}{*}{ Perfect of recent past } & Activities & 4 & \multirow{3}{*}{$2.43 \%$} \\
\hline & Accomplishments & 2 & \\
\hline & Achievements & 3 & \\
\hline & Total & 371 & $100 \%$ \\
\hline
\end{tabular}

\footnotetext{
${ }^{13}$ Boyland (1995) presents corpus data to show that in the structure like would+ have+past participle, have is becoming more tightly bound to would than the past participle.

${ }^{14}$ This count does not include perfect progressive, which will be discussed later in this section.
} 
It is also interesting to note from the table that the specific perfect meaning is positively correlated with situation types. The perfect of result is only compatible with telic situations, because only these situations can possibly yield any result. The perfect of persistent situation is only felicitous with durative situations, because only these situations can persist over time ${ }^{15}$. Only dynamic situations are compatible the perfect of recent past, because only these situations can happen in the recent past. The experiential perfect does not have any restrictions on the temporal features of a situation and can occur with all situation types. Although no instances of a semelfactive were found in our corpus, it can be safely assumed, on the basis of its temporal features (c.f. section 1), that a semefactive can have the perfect meanings of recentness (e.g., The town hall clock has just struck 12) or experientiality (e.g., He has never beaten his dog) but is incompatible with result. When a semelfactive denotes an iterative multiple event, it can even signal persistence (e.g., He has tapped on his old typewriter since noon). While the perfect of result, the experiential perfect, and the perfect of recent past are perfecctive in nature, the perfect of persistent situation is imperfectvie (c.f. also Mourelatos, 1981:195). As such, there are variations in the Chinese translation of the English perfect.

Comrie (1976: 56) defines the perfect as “the continuing relevance of a previous situation”. The clearest manifestation of such relevance is the result of a completed situation. Chinese has the completive aspect signaled by RVCs. The interaction between the actual aspect marker -le and telic situations also results in completive readings (c.f. Xiao, 2001). Therefore, the perfect of result is most frequently (70.78\%) translated with the actual or completive viewpoint (or the complex viewpoint of actual completive aspect) in Chinese unless the translator chooses to introduce a shift in situation type, as show in Table 8 below.

Discounting the instances of situation type shifts and paraphrases in translations, the rate of overt marking over LVM registers 2.77:1. Of the 56 unmarked cases, 31 can actually take -le, which is left out for discourse reasons in translation. The remaining cases cannot take -le because:

\footnotetext{
${ }^{15}$ While accomplishments are in principle compatible with the perfect meaning of persistent situation, the frequency of such occurrences is expected to be extremely low (and no instance is found in our corpus), because telic situations go more naturally with perfect of perfective types.
} 
- $\quad$ situation types have shifted to ILS ${ }^{16}$ that do not need to be marked to have closed readings;

- $\quad$ translators have chosen an imperfective viewpoint;

- $\quad$ or the verb constellations in question function as attributives that do not normally take -le.

Table 8: Translation patterns of the perfect of result:

\begin{tabular}{|l|l|l|l|l|l|l|l|l|l|l|l|}
\hline \multirow{2}{*}{$\begin{array}{l}\text { Situation } \\
\text { type }\end{array}$} & \multicolumn{5}{|c|}{ Marked } & \multicolumn{2}{c|}{ LVM } & \multirow{2}{*}{ Para- } & Total \\
\cline { 2 - 11 } & $-l e$ & $R V C$ & Neg. & RVC...-le & RVC...Neg. & $-z h e^{17}$ & yi/yijing & Null & phrase & \\
\hline ACC & 28 & $5^{18}$ & 1 & 7 & 0 & 0 & 6 & 8 & 1 & 56 \\
\hline ACH & 38 & 31 & 4 & 36 & 5 & 1 & 23 & 19 & 6 & 163 \\
\hline Total & 66 & 36 & 5 & 43 & 5 & 1 & 29 & 27 & 7 & 219 \\
\hline
\end{tabular}

Furthermore, there are 29 unmarked cases taking the adverb yi/yijing "already" to lexicalize the perfect meaning of result. While already frequently occurs in perfect constructions, this adverb alone can signal current relevance, as evidenced by the possible substitution of the resultative perfect with the simple aspect taking already in American English and some dialects of British English (c.f. Biber, Johansson, Leech \& Finegan, 1999: 463) ${ }^{19}$. Like its English equivalent already, yi/yijing signals the actualization of a situation in the period up to the present.

Chinese has the experiential aspect, which is marked by -guo. Therefore, translation of the experiential perfect is in principle quite straightforward. The perfect of experience and the

\footnotetext{
${ }^{16}$ As the perfect of result presents the result of a previous situation, it is quite natural for a situation type shift to ILS. In fact, resultative perfect has sometimes referred to as "stative perfect” (e.g., Moens, 1987: 101).

17 The durative aspect marker -zhe is intrinsically incompatible with achievements. But in the translation pair involved (<s n="L1E_5836"> It has come to define not only a city, but an entire nation and continent. $<$ s $><\mathrm{s}$ $\mathrm{n}=$ "L2C_5836"> 它已经不仅仅标志着一座城市, 而且象征着一个国家和一个大洲。 $\langle/ \mathrm{s}\rangle)$, there is a shift in situation type from achievement to ILS in the Chinese translation.

${ }^{18}$ Accomplishments in the English source data first underwent situation type shift to achievements when RVCs were added.

${ }^{19}$ Dahl (1985) notes that there are at least 4 types of periphrasic constructions for perfect: 1 ) copular plus past participle (e.g., Hindi, Bulgarian); 2) auxiliary have plus past participle (e.g., most Germanic and Romance languages; 3) main verb plus particle already (e.g., Yoruba, Isekiri); and 4) constructions historically developed from the verb meaning finish or throw away (e.g., Sango, Ewe).
} 
experiential aspect interact felicitously with all situation types. When stative situations (i.e., ILSs and SLSs) take the experiential aspect in Chinese, they must be marked overtly. With dynamic situations, the experiential aspect marker can be optionally left out in discourse, as can be seen in Table 9:

Table 9: Translation pattern of the experiential perfect:

\begin{tabular}{|c|c|c|c|c|c|}
\hline \multirow[t]{2}{*}{ Situation type } & \multicolumn{2}{|c|}{ Marked } & \multicolumn{2}{|c|}{ LVM } & \multirow[t]{2}{*}{ Total } \\
\hline & $-g u o$ & Negation & Ceng/cengjing & Null & \\
\hline ILS & 1 & 0 & 0 & 0 & 1 \\
\hline SLS & 1 & 0 & 0 & 0 & 1 \\
\hline ACT & 8 & 0 & 0 & 8 & 16 \\
\hline ACC & 5 & 0 & 2 & 3 & 10 \\
\hline $\mathrm{ACH}$ & 12 & 1 & 1 & 3 & 17 \\
\hline Total & 27 & 1 & 3 & 14 & 45 \\
\hline
\end{tabular}

The marked/LVM ratio in translations of the experiential perfect is $1.65: 1$. Of the 17 unmarked cases, with the exception of one instance that optionally underwent a situation type shift from accomplishment to ILS in the process of translation ${ }^{20}$, all of the others can be optionally marked overtly with -guo. This is because the experiential aspect in Chinese has exactly the same meaning as the English perfect of experience. The adverb ceng/cengjing “once, ever” used either alone or in combination with -guo, indicates that an event once happened or a state once held and strengthens the force of experientiality.

The perfect of persistent situation refers to a situation which started in the past and persists up to, and perhaps even beyond, the present. This type of perfect is characteristic of English (Comrie, 1976: 60). In Chinese, there is no dedicated aspect marker for this meaning.

It can be seen in Table 10 below that situations that go most naturally with the perfect of persistent situations have the feature values of [+durative] and [-telic]. This is because punctual situations do

\footnotetext{
$20<$ s n="L1E_1767"> We've been all the way to the moon and back, but have trouble crossing the street to meet the new neighbor. $</ \mathrm{s}><\mathrm{s} \mathrm{n}=$ "L2C_1767" $>$ 我们能够往返于地球与月球之间, 却不乐于穿过 马路 向 新 邻居 问好。 $</ \mathrm{s}>$
} 
not persist or continue over time, and telic situations must be presented with a perfective viewpoint for its final spatial endpoint to be visible.

Table 10: Translation pattern of the persistent perfect:

\begin{tabular}{|l|l|l|l|l|l|l|l|l|l|}
\hline \multirow{2}{*}{$\begin{array}{l}\text { Situation } \\
\text { type }\end{array}$} & \multicolumn{4}{|c|}{ Marked } & \multicolumn{3}{|c|}{ LVM } & Paraphrase & Total \\
\cline { 2 - 9 } & - -le & -zhe & zai & Negation & yizhi & yijing & Null & & \\
\hline ILS & 13 & 1 & 0 & 4 & 11 & 5 & 25 & 0 & 59 \\
\hline SLS & 0 & 0 & 0 & 0 & 1 & 0 & 0 & 0 & 1 \\
\hline ACT & 3 & 0 & 2 & 1 & 5 & 5 & 21 & 1 & 38 \\
\hline Total & 16 & 1 & 2 & 5 & 17 & 10 & 46 & 1 & 98 \\
\hline
\end{tabular}

Translations of the English perfect of persistent situation mainly take the LVM form, though there are exceptions. As the perfect of persistent situation is imperfective in nature, the durative marker -zhe and the progressive marker zai are expected to be compatible with this perfect meaning provided that no conflict occurs in the interaction between situation aspect and viewpoint aspect (the progressive zai only goes well with dynamic situations). With ILSs, even the actual aspect marker -le can be used ${ }^{21}$, because ILSs taking -le signal ingressiveness and only define the left boundary (i.e., the initial endpoint) of a situation while the right boundary is left open. There are 3 activities in the English source data translated into Chinese with the actual -le, but 2 of them have undergone situation type shift from activities to achievements (translation pairs 4223 and 4227) ${ }^{22}$. The other example is interesting and deserves more discussion: He has studied the state's PE programmes for two decades (<s n="L2C_1724">) 他已对该州的体育课程作了 20 年 的研究 (<s n="L2C_1724">). An activity taking -le is reasonably expected to be presented as a whole, including its final endpoint. For example, 他对该州的体育课程作了 20 年 的研究 He studied the state's PE programmes for two decades has a closed reading and

${ }^{21}$ Of the 13 instances of ILS of perfect of persistent situation, 5 underwent situation type shift from ILSs to achievements taking -le in Chinese translations to indicate perfect of result.

$22<$ s n="L1E_4223"> Since Piaget, the territory has been widely colonized by those who write about women's ways of knowing, Afrocentric ways of knowing, even the computer's ways of knowing. </s><s n="L2C_4223"> 自从皮雅杰以来, 这块领地已得到了那些撰写女性认知方式、非洲中心认知方式, 甚 至是 计算机认知 方式的作家们的广泛开拓。 $</ \mathrm{s}><\mathrm{s} n=" L 1 E \_4227 ">$ In the past decade Piaget has been vigorously challenged by the current fashion of viewing knowledge as intrinsic property of the brain. $</ \mathrm{s}><\mathrm{s}$ n="L2C_4227" > 在过去的十年里, 皮雅杰的理论受到了现在流行的一种观点的 极大挑战, 后者 把知识看作 是头脑的固有 特征。 $</ \mathrm{s}>$ 
indicates that he is no longer involved in that study. To indicate the contrary, the combination of the actual -le and the change-of-state (COS) le must be used, as in他 对 该 州 的 体育课程 作了 20 年的研究了 He has studied the state's PE programmes for two decades (c.f. Henne et al, 1977:113). In the corpus example, however, only the actual -le, instead of its combination with the COS le, is used. Yet the sentence still has an open-ended reading rather than the expected closed reading. This is because the adverb yi "already" is used. As noted earlier in this section, yi/yijing "already" signals current relevance of an actualized situation. As an activity does not have a spatial final endpoint, its current relevance is only related to its persistence up to the present. As such, when yi/yijing is used, its current relevance reading overrides its actualization reading. This also explains why these adverbs appear so frequently in LVM sentences with perfect meanings.

As can seen from Table 10, another adverb which is often used to lexicalize the perfect of persistent situation is yizhi (or sometimes yixiang) "all the time". It indicates that a situation occurs all of the time, including at least past and the present, though its future occurrence is speculative. The temporal frame of this lexical meaning coincides with the perfect of persistent situation, thus explaining the frequent occurrence of yizhi/yixiang with this perfect meaning.

The perfect of recent past simply indicates "temporal closeness" (Comrie, 1976: 60) or the nearness of a past situation. Syntactically, its difference with the perfect of result lies mainly in the presence or absence of adverbs such as recently or just, but this is not absolute, because temporal nearness may present itself in context. Semantically, it is sometimes very difficult, or impossible, to distinguish the perfect of recent past from the perfect of result in the absence of relevant distinguishing adverbs (c.f. Leech, 1971: 34, Brinton, 1988:12). This is particularly true when telic situations are involved ${ }^{23}$. When translated into Chinese, the perfect of recent past is marked by the actual aspect with a past time reference.

\footnotetext{
${ }^{23}$ Atelic situations do not have a final spatial endpoint and are thus irrelevant to perfect of result. See discussions earlier in this section.
} 
Table 11: Translation pattern of the perfect of recent past:

\begin{tabular}{|l|l|l|l|l|l|}
\hline \multirow{2}{*}{ Situation type } & Marked & \multicolumn{2}{|c|}{ LVM } & \multirow{2}{*}{ Paraphrase } & \multirow{2}{*}{ Total } \\
\cline { 2 - 4 } & - -le & ganggang & Null & & \\
\hline ACT & 2 & 0 & 1 & 1 & 4 \\
\hline ACC & 1 & 1 & 0 & 0 & 2 \\
\hline ACH & 0 & 3 & 0 & 0 & 3 \\
\hline Total & 3 & 4 & 1 & 1 & 9 \\
\hline
\end{tabular}

As the table shows, the translation of the perfect of recent past is quite straightforward. With the exception of one instance that is paraphrased as a noun phrase (<s n="L1E_5361"> A 25-year-old fanatic, Yigal Amir, was outraged that the two leaders have shaken hands. $</ s><s$ n="L2C_5361"> 一个 25 岁的狂热分子, 伊加尔 - 阿米尔, 被这两个领导 人 的 握手 所 激怒。 $</ \mathrm{s}>$ ), all of the other examples either take -le or are covertly marked. The adverb gang(gang) "just" or similar expressions can be used to make temporal nearness explicit.

The English pluperfect has frequently been thought of as the "past in the past". As such, it can be argued that the pluperfect only goes well with a past time reference. Comrie (1985:67) argues that "Since the pluperfect indicates a time point before some other time point in the past, it follows that the situation referred to by the pluperfect is itself located in the past”. A situation located in the past must have been actualized, completed or mentally experienced. Therefore, in Chinese translations, the actual aspect, the completive aspect and the experiential aspect are frequently employed (either marked overtly or covertly) to present this kind of situation, as shown in Table 12 below. It can be seen from the table that $90 \%$ of the situations referred to by the English pluperfect are presented with these three perfective viewpoints in Chinese translations ${ }^{24}$, where the past time references are normally implied in context. Sometimes adverbs such as yuan/yuanlai/yuanben "formerly", yiqian "before", zai ci zhiqian "before that" are used to make these past time references explicit. It should be noted that ILSs do not interact felicitously with the progressive zai and achievements are incompatible with the durative -zhe. The ILS taking zai (L1E_0473) and the achievement taking -zhe (L1E_2521) given in the table were shifted to

\footnotetext{
${ }^{24}$ The actual -le has sometimes been argued to indicate both perfective aspect and relative past time reference (e.g., Comrie, 1976: 58) while the experiential aspect is often referred to as aspect of “indefinite past” (e.g., Chao, 1968).
} 
activities that could take these markers. As a special case of the perfect, the English pluperfect does not rule out the possibility of situations referred to by the pluperfect being presented with an imperfective viewpoint like the progressive or the durative.

Table 12: Translation patterns of the pluperfect:

\begin{tabular}{|c|c|c|c|c|c|c|c|c|c|c|c|c|c|c|}
\hline \multirow[t]{3}{*}{$\begin{array}{l}\text { Situ. } \\
\text { type }\end{array}$} & \multicolumn{3}{|c|}{ actual } & \multirow{3}{*}{$\begin{array}{l}\begin{array}{l}\text { com } \\
\mathrm{pl}\end{array} \\
\mathrm{mkd} \\
R \\
V \\
C \\
\end{array}$} & \multirow{2}{*}{\multicolumn{2}{|c|}{$\begin{array}{l}\text { actual } \\
\text { completive } \\
\text { mkd }\end{array}$}} & \multicolumn{2}{|c|}{ experience } & \multicolumn{2}{|l|}{ prog } & \multicolumn{2}{|c|}{ durative } & \multirow[t]{3}{*}{ para } & \multirow[t]{3}{*}{ Total } \\
\hline & \multicolumn{2}{|c|}{ Mkd } & \multirow{2}{*}{$\begin{array}{l}\mathrm{L} \\
\mathrm{V} \\
\mathrm{M}\end{array}$} & & & & \multirow{2}{*}{$\begin{array}{c}\mathrm{mkd} \\
-g u o\end{array}$} & \multirow{2}{*}{$\begin{array}{l}\mathrm{L} \\
\mathrm{V} \\
\mathrm{M}\end{array}$} & \multirow{2}{*}{$\begin{array}{l}\mathrm{mkd} \\
z a i\end{array}$} & \multirow{2}{*}{$\begin{array}{l}\mathrm{L} \\
\mathrm{V} \\
\mathrm{M}\end{array}$} & \multirow{2}{*}{$\begin{array}{l}\text { mkd } \\
\text {-zhe }\end{array}$} & \multirow{2}{*}{$\begin{array}{l}\mathrm{L} \\
\mathrm{V} \\
\mathrm{M}\end{array}$} & & \\
\hline & $-l e$ & neg & & & $\begin{array}{l}-l e+ \\
R V \\
C\end{array}$ & $\begin{array}{l}\text { neg } \\
+R \\
V C \\
\end{array}$ & & & & & & & & \\
\hline \multirow{7}{*}{ ILS } & 1 & 4 & 22 & & & & & & & & & & & 27 \\
\hline & & & & 1 & & & & & & & & & & 1 \\
\hline & & & & & 1 & & & & & & & & & 1 \\
\hline & & & & & & & 2 & 1 & & & & & & 3 \\
\hline & & & & & & & & & 1 & & & & & 1 \\
\hline & & & & & & & & & & & 1 & & & 1 \\
\hline & & & & & & & & & & & & & 4 & 4 \\
\hline \multirow[t]{2}{*}{ SLS } & 1 & & 1 & & & & & & & & & & & 2 \\
\hline & & & & & & & & & & & 1 & & & 1 \\
\hline \multirow{7}{*}{ ACT } & 6 & & 11 & & & & & & & & & & & 17 \\
\hline & & & & 2 & & & & & & & & & & 2 \\
\hline & & & & & 3 & & & & & & & & & 3 \\
\hline & & & & & & & 8 & 5 & & & & & & 13 \\
\hline & & & & & & & & & 2 & 1 & & & & 3 \\
\hline & & & & & & & & & & & 3 & & & 3 \\
\hline & & & & & & & & & & & & & 3 & 3 \\
\hline \multirow{5}{*}{ ACC } & 13 & & 12 & & & & & & & & & & & 25 \\
\hline & & & & 4 & & & & & & & & & & 4 \\
\hline & & & & & 6 & & & & & & & & & 6 \\
\hline & & & & & & & 4 & 2 & & & & & & 6 \\
\hline & & & & & & & & & & & & & 5 & 5 \\
\hline \multirow[t]{6}{*}{$\mathrm{ACH}$} & 25 & 3 & 32 & & & & & & & & & & & 60 \\
\hline & & & & 25 & & & & & & & & & & 25 \\
\hline & & & & & 19 & 3 & & & & & & & & 22 \\
\hline & & & & & & & 11 & 1 & & & & & & 12 \\
\hline & & & & & & & & & & & 1 & & & 1 \\
\hline & & & & & & & & & & & & & 3 & 3 \\
\hline Total & 46 & 7 & 78 & 32 & 28 & 3 & 25 & 9 & 3 & 1 & 6 & 0 & 15 & 253 \\
\hline
\end{tabular}


The future perfect is similar to the pluperfect except that the time reference is in the future rather than in the past. The future time reference can be provided explicitly by a temporal adverbial, as in By the end of 2001, a total of 250,000 panellists in 30 countries will have been recruited, collectively representing 92 per cent of the worlds Internet users (L1E_3179) 到 2001 年底， 将在 30 个国家吸收总共 25 万名专门小组成员, 共同 代表 $92 \%$ 的世界互 联网 用户 (L2C_3179), or it can be given implicitly by context, as in If Zhang and Ecker's hybrid produces anything like that anticipated windfall, it will have proven more than Chinese enough (L1E_3475) 如张导和埃克的联袂 制作能获预期 的成功，那将足以 证明：歌剧 不仅仅 只是 够 中国 味儿 而已 (L2C_3475). Only 3 instances of the future perfect were found in our data, all of which indicate that when situations referred to by the future perfect are translated into Chinese, the perfect meanings are lost and these situations are presented perfectively with a future time reference.

\section{The perfect progressive aspect}

The complex viewpoint of the perfect progressive is a combination of possible perfect meanings and possible progressive meanings. In such combinations, the most likely perfect meaning is the perfect of persistent situation, though other perfect meanings are also possible (c.f. Comrie, 1976: 62). The progressive component in the combination gives the complex viewpoint its meaning of temporariness and incompleteness (c.f. Leech, 1971: 44-46). Comrie (ibid) argues that the distribution of the progressive and non-progressive forms in the perfect is "essentially the same" as in the present tense: "the non-Progressive form must be used with stative verbs...while other verbs, unless habitual, will normally be in the Progressive”. This argument, however, has missed the point of the semantic differences between the perfect and the perfect progressive as observed in Leech (ibid). Furthermore, non-stative verbs indicating habituality can actually take the progressive form, as in $<\mathrm{s} n=" L 1 E \_1239 ">$ "Blumberger's been buying the bread here. $</ \mathrm{s}><\mathrm{s}$ n="L2C_1239"> "布卢姆伯杰一直 都 在 您 这里 买 干面包。</s $>$

In Chinese translations, while the perfect progressive may shift towards the progressive or the perfect, depending on the situation type involved and the translator's choice of viewpoint, both perfect and progressive meanings can be retained in most cases, with the perfect being lexicalized 
by temporal adverbs such as yizhi "all the time" while the progressive being signaled by the progressive marker zai or implied in contexts ${ }^{25}$.

Table 13: Translation pattern of the perfect progressive:

\begin{tabular}{|c|c|c|c|c|c|c|c|c|}
\hline \multirow{3}{*}{$\begin{array}{l}\text { Situation } \\
\text { type }\end{array}$} & \multicolumn{5}{|c|}{ Perfect } & \multicolumn{2}{|c|}{ Progressive } & \multirow[t]{3}{*}{ Frequency } \\
\hline & \multicolumn{2}{|c|}{ Marked } & \multicolumn{3}{|c|}{ LVM } & \multirow{2}{*}{$\begin{array}{l}\text { Marked } \\
\text { zai }\end{array}$} & \multirow{2}{*}{$\begin{array}{l}\text { LVM } \\
\text { Null }\end{array}$} & \\
\hline & $-l e$ & Negation & yijing & yizhi & Null & & & \\
\hline \multirow[t]{3}{*}{ ILS } & & & & + & & & + & 2 \\
\hline & & & + & & & & + & 1 \\
\hline & + & & & & & & + & 1 \\
\hline \multirow[t]{4}{*}{ ACT } & & & & + & & + & & 6 \\
\hline & & & & + & & & + & 2 \\
\hline & + & & + & & & & & 2 \\
\hline & & + & & & & & + & 1 \\
\hline ACC & & & & + & & + & & 1 \\
\hline Total & & & & & & & & 16 \\
\hline
\end{tabular}

In our data, only the perfect of persistent situation is involved in the perfect progressive. As Table 13 above shows, only the perfect meaning is retained with ILSs, as this situation type is strictly incompatible with the progressive. However, it is sometimes possible to use the durative marker -zhe to indicate the ongoing feature of a durative situation. For example, Because we've been living with the rogue DNA (the proviruses) for a long time, the diseases it causes have evolved into fairly harmless forms and don't cause us problems (L1E_4683) can be translated as 因为 我们 长期 以来一直与变性 的 DNA ( 前 病毒 ) 共处 (着), 所以由 它引发 的疾病 已不能造成危害，也不会给我们带来麻烦了 (L2C_4683). Similarly, On the positive side, people and pigs have been living in close contact for thousands of years and only a few illnesses have been passed on to us (L1E_4673) is translatable with 实际上，人类和猪 数千 年 以来一直 密切相处着，只有少数 起源于 猪 的 疾病 传染给了人类 in addition to the original translation 实际上, 人类和 猪 密切相处已有数千年之

\footnotetext{
${ }^{25}$ If no conflict occurs in the interaction between situation aspect and viewpoint aspect, progressive marker zai can actually be added to LVM progressives, as in two such examples in our data: <s n="L1E_2425"> He has been telling you he wrote them." $</ \mathrm{s}><\mathrm{s} \mathrm{n}="$ L2C_2425" $>$ 他一直 (在) 对你说, 这些诗是他写的。 "</s $><$ s n="L1E_5394" $>$ He also confesses that, desperate for money to pay his gambling debts, he has been stealing from houses in the town. $</ \mathrm{s}><\mathrm{s} n=" \mathrm{~L} 2 \mathrm{C} \_5394 ">$ 同时汤姆还坦白承认，因急需现款偿还 奢债，他一直 (在) 从 镇民 家中盗窃 财物。 $</ \mathrm{s}>$
} 
久 ....(L2C_4673).

With situation types that can take the progressive, i.e., activity and accomplishment in our case, the translator's choice of viewpoint plays a role. This means that the focus can fall on either the perfect or the progressive. As far as activity and accomplishment are concerned, when the perfect progressive takes a durative temporal adverbial (e.g., for 3 months), it is the translator's choice to place the focus on the perfect or the progressive meaning. For example, He's been working hard for three months drawing a plan for a new city hall (L1E_1235) can be translated as 他 已经 为 新市政厅的设计忙碌了三个月 (L2C_1235), or optionally it can be translated as 三 个月来他一直在为新市政厅 的设计 图纸 忙碌 (our translation). Conversely, $M y$ dog has been chasing cars for years, but if he ever caught one, he wouldn't know what to do with it (L1E_0574) can be translated as 我的狗多年来一直在追逐汽车，但如果它 真的抓住了一辆, 就不知道如何是好了 (L2C_0574), or it can be translated as 我 的狗已经追逐汽车多年了 ... (our translation). If there is no durative adverbial, as with most cases in our data, only the translation pattern with yizhi and zai is appropriate.

When the pluperfect interacts with the progressive aspect, the result is the pluperfect progressive, which signals progressiveness with a relative past time reference. While all situation types compatible with the progressive are expected to interact felicitously with the pluperfect progressive, only activities and accomplishments were found in our data.

Table 14: Translation pattern of the pluperfect progressive:

\begin{tabular}{|c|c|c|c|c|c|c|c|c|}
\hline \multirow{3}{*}{$\begin{array}{l}\text { Situation } \\
\text { Type }\end{array}$} & \multicolumn{4}{|c|}{ Perfect } & \multicolumn{2}{|c|}{ Progressive } & \multirow{3}{*}{$\begin{array}{l}\text { Durative } \\
\text { Marked } \\
\text {-zhe }\end{array}$} & \multirow[t]{3}{*}{ Frequency } \\
\hline & \multicolumn{2}{|c|}{ Marked } & \multicolumn{2}{|c|}{ LVM } & \multirow{2}{*}{$\begin{array}{l}\text { Marked } \\
\text { zai } \\
\end{array}$} & \multirow{2}{*}{$\begin{array}{l}\text { LVM } \\
\text { Null } \\
\end{array}$} & & \\
\hline & -le & $R V C$ & yizhi & Null & & & & \\
\hline \multirow{6}{*}{ ACT } & & & & & & & + & 1 \\
\hline & + & & & & & & & 1 \\
\hline & & + & & & & & & 1 \\
\hline & & & + & & + & & & 1 \\
\hline & & & & + & & & & 2 \\
\hline & & & & & & + & & 1 \\
\hline ACC & & & & & & + & & 1 \\
\hline \multicolumn{8}{|l|}{ Total } & 8 \\
\hline
\end{tabular}

Like the perfect progressive, the pluperfect progressive only involves the perfect meaning of a 
persistent situation. As such, the situations referred to by the English pluperfect progressive can be translated into Chinese with the progressive or the durative aspect unless the translator chooses to present them perfectively or a shift in situation type prohibits their taking the progressive zai or the durative -zhe. As Table 14 shows, 4 situations are presented perfectively (one marked overtly with -le, one by RVC, and 2 marked covertly) while all of the others are presented as progressive or durative. It is interesting to note that all of the 4 situations presented perfectively shifted from activities to ILSs (translation pairs 1823 and 6071) or achievements (translation pairs 3852 and 5500) and are thus incompatible with the progressive aspect, though all of these situations can be optionally translated with the progressive zai if the translator chooses to do so.

\section{The simple aspect}

Simple forms in English (simple past, simple present and simple future) have been discussed extensively within the context of tense distinctions while their aspectual significance has been virtually ignored (c.f. Brinton, 1988:15). It can be argued that while simple forms are not formally marked for aspect, they convey aspectual meaning as well as tense meaning. They convey the simple aspect. Unlike the progressive, the perfect or the complex viewpoint of perfect progressive discussed in previous sections, the simple aspect presents a situation without aspectual modification $^{26}$. The simple aspect is typically used to present situations that occur once, are repeated, are habitual or are timeless. When the simple aspect interacts with tense, we have the simple past, the simple present and the simple future.

The simple past typically locates a situation in time prior to the present moment ${ }^{27}$. In the simple past, there is no distinction between single situations and habits ${ }^{28}$ (c.f. Leech, 1971: 9; Brinton, 1988: 250), though the auxiliary used to does unequivocally indicate a past habit. When a situation referred to by the English simple past is translated into Chinese, it is possible to present it either perfectively or imperfectively, depending on its situation type and the translator's choice of

\footnotetext{
${ }^{26}$ Hatcher (1951: 259-260) argues that the simple form has no aspectual meaning and is indifferent to aspect.

${ }^{27}$ In some daily conversation, simple past can also refer to the speaker's present state of mind to make a request tentative and thus more polite (c.f. Leech, 1971: 11; Biber, Johansson, Leech and Finegan, 1999: 454). But this extension of simple past is restricted in conversation and was not found in our high-frequency data.

${ }^{28}$ The former is referred to as unitary past and the latter as habitual past in Leech (1971:9).
} 
viewpoint, because the English simple aspect does not modify a situation aspectually.

Table 15: Translation patterns of the simple past:

\begin{tabular}{|l|l|l|l|l|l|l|l|l|l|}
\hline \multicolumn{3}{|c}{ Aspect marking } & ILS & SLS & ACT & SEM & ACC & ACH & Total \\
\hline \multirow{4}{*}{ Actual } & \multirow{2}{*}{ Mkd } & - le & & 1 & 3 & & 9 & 18 & 31 \\
\cline { 2 - 10 } & & Neg. & 4 & & 1 & & & 3 & 8 \\
\hline & LVM & Null & 19 & & 18 & & 32 & 41 & 110 \\
\hline Completive $^{29}$ & Mkd & RVC & & & 1 & & 1 & 25 & 27 \\
\hline $\begin{array}{l}\text { Actual } \\
\text { Completive }\end{array}$ & \multirow{2}{*}{ Mkd } & -le...RVC & & & & & 5 & 11 & 16 \\
\hline & & Neg...RVC & 1 & & & & & & 1 \\
\hline Experiential & Mkd & -guo & & & 1 & & 2 & & 3 \\
\cline { 2 - 10 } & LVM & Null & & & & & 1 & & 1 \\
\hline \multirow{2}{*}{ Progressive } & Mkd & Zai & & & & & & & 0 \\
\cline { 2 - 10 } & LVM & Null & & & 2 & & & & 2 \\
\hline \multirow{2}{*}{ Durative } & Mkd & -zhe & & & 6 & 1 & & & 7 \\
\cline { 2 - 10 } & LVM & Null & 3 & & 5 & & & & 8 \\
\hline Inceptive & Mkd & -qilai & & & 1 & & & & 1 \\
\hline Habitual & LVM & Null & 6 & & 6 & & 5 & & 17 \\
\hline Total & & & 33 & 1 & 44 & 1 & 55 & 98 & 232 \\
\hline
\end{tabular}

There are 3,468 instances of the simple past form in our corpus. To make the data manageable, we chose to study only those with a frequency of 15 or above, totaling 232 instances. As Table 15 above shows, except for the delimitative aspect marked by verb reduplication and the successive aspect marked by -xiaqu, all other basic viewpoints were found in Chinese translations ${ }^{30}$. It is also interesting to note that in our frequent data, $84.5 \%$ of the situations referred to by the English simple past are presented with a perfective viewpoint in Chinese translations. This is as expected. The English simple past normally refers to situations that completed or terminated in the past. As such, it has been sometimes been called perfective past in the literature (e.g., Brinton, 1988: 16). While perfective viewpoints are not formally marked in English, they have to be made explicit in Chinese translations. The high frequency of perfective viewpoints in Chinese translations is closely related to the text types included in the corpus, which primarily covers narratives ${ }^{31}$.

\footnotetext{
${ }^{29}$ One instance of ILS, one activity and 6 accomplishments were shifted to achievements when an RVC was attached to them, because RVCs not only perfectivize a situation but also contribute to situation aspect.

${ }^{30}$ The absence of these viewpoint aspects in the frequent data does not exclude the possibility of them occurring in the low-frequency data.

${ }^{31}$ Perfective viewpoints normally appear in foregrounded clauses to carry the narration forward, while imperfective
} 
Chinese does not formally mark habituality. The expressions for a present habit and a past habit take the same LVM form, though in the case of habitual past, the past time reference is implied in contexts or made explicit by temporal adverbials. Habitual situations in the past referred to by the English simple past are, therefore, not marked in Chinese translations.

The simple present in English normally refers to states, i.e., statements made "for all time" 32 (Leech, 1971: 2) and habitual situations, though it may be extended, in the right circumstances, to mark predetermined future situations, to narrate past events, and to indicate events in progress (Leech, ibid: 1-8; Comrie, 1985: 36-41; Brinton, 1988: 16). There are 144 instances of the simple present with a frequency of 15 or above in our corpus ${ }^{33}$, as shown in Table 16. It can be seen from the table that the English simple present is most commonly used to present states whereas the instantaneous use of the simple present to refer to ongoing situations is not found in the high-frequency data we examined ${ }^{34}$. The simple present marking past accounts for a large proportion simply because of the high frequency of "verbs of communication" and of the “fictional use” of the simple present ${ }^{35}$ (Leech, 1971: 7, 14) in our corpus.

Table 16: Translation pattern of the simple present in the corpus:

\begin{tabular}{|l|l|l|l|l|l|l|l|l|l|}
\hline Meaning & Aspect marking & ILS & SLS & ACT & SEM & ACC & ACH & Freq. & Total \\
\hline
\end{tabular}

viewpoints often show up in backgrounded clauses to provide background information (c.f. Hopper, 1979:221; Christensen, 1994).

32 This category may include timeless situations, general truth, generic situations, proverbial occurrences and scientific, mathematical and geographical statements.

${ }^{33}$ The figure does not include words of other parts of speech that were incorrectly tagged as VV0 or VVZ, nor does it include 19 instances of imperatives in which verbs are tagged as VV0.

${ }^{34}$ One instance of this kind is found in our low-frequency data: Here come the Jewels (L1E_4012) 朱厄尔一家人 来 $了$ (L2C_4012). The most natural way to express this meaning in Chinese, as the translation shows, is to use the COS le.

${ }^{35}$ Reporting verb (e.g., say, tell) referring to the initiation of a message in the past can take simple present form because "the verbal meaning has been transferred from the initiating end to the receiving end of the message. The communication is still in force for those who have received it” (Leech, 1971: 7). In literary works, novelists or story-tellers may narrate past or imaginary happenings with simple present as if they were going on at the present time to achieve dramatic heightening (c.f. Leech, ibid: 6, 14). 


\begin{tabular}{|c|c|c|c|c|c|c|c|c|c|c|}
\hline \multirow[t]{3}{*}{ State } & \multirow[t]{2}{*}{ Marked } & -le & 1 & & & & 2 & 1 & 4 & \multirow[t]{3}{*}{70} \\
\hline & & RVC & & & & & & 3 & 3 & \\
\hline & LVM & Null & 43 & & 9 & & 5 & 6 & 63 & \\
\hline \multirow[t]{3}{*}{ Habit } & \multirow[t]{2}{*}{ Marked } & -le & & & & & & 1 & 1 & \multirow{3}{*}{16} \\
\hline & & RVC & & & & & & 3 & 3 & \\
\hline & LVM & Null & 2 & & 5 & 1 & 1 & 3 & 12 & \\
\hline \multirow[t]{5}{*}{ Past } & \multirow[t]{4}{*}{ Marked } & -le & 1 & & & & 2 & & 3 & \multirow{5}{*}{44} \\
\hline & & RVC & & & 1 & & & 5 & 6 & \\
\hline & & -le+RVC & & & & & 1 & & 1 & \\
\hline & & -qilai & & & & & & 1 & 1 & \\
\hline & LVM & Null & 5 & 1 & 4 & 1 & 13 & 9 & 33 & \\
\hline \multirow[t]{4}{*}{ Future } & \multirow[t]{3}{*}{ Marked } & RVC & & & & & & 1 & 1 & \multirow{4}{*}{14} \\
\hline & & -le+RVC & & & & & & 2 & 2 & \\
\hline & & Negation & & & & & & 1 & 1 & \\
\hline & LVM & Null & & & 3 & & 3 & 4 & 10 & \\
\hline \multicolumn{3}{|l|}{ Total } & 52 & 1 & 22 & 2 & 27 & 40 & & 144 \\
\hline
\end{tabular}

A study of high frequency verbs shows that when situations taking the simple present aspect are translated into Chinese, they are most likely to take LVM form (81.94\%). This is especially true when the English simple present refers to statements made for all time (90\%). As far as situation types are concerned, [-telic] situations are more likely to take LVM form (96.1\%) than [+telic] situations (65.67\%). It should be noted, however, that aspect is simply related to the temporal shape of a situation and is non-deictic temporally. As such, aspect markers such as -le, RVC or -qilai can be used in past, future, or timeless situations.

The simple future refers to a future time reference. While it is debatable whether there is a formal future tense in English (c.f. Comrie, 1985: 43-48; Biber, Johansson, Leech \& Finegan, 1999: 456), we will not go into this debate in this paper. Rather we will only focus on how future time reference in English is translated into Chinese. The simple future is marked by will, shall and be going to. As we noted previously, the simple present can also mark future time reference. But it should be noted that there is a basic difference between the simple present and the simple future when they mark futurity. In main clauses, the simple present can only be used with future time reference in highly specific circumstances, i.e., where the situation in question is presented as being scheduled or predetermined, as in The train leaves at 6 (c.f. Comrie, ibid: 49). *It rains tomorrow is ill formed unless God is talking or advances in meteorology have made it possible for 
humans to schedule rain (c.f. Comrie, ibid: 48). In contrast, the simple future does not have such restrictions. In this paper, we will only discuss future time reference marked by the simple future. There are 242 instances of the simple future in our data ${ }^{36}$, as distributed in Table 17:

Table 17: Translation pattern of the simple future:

\begin{tabular}{|l|l|l|l|l|l|l|l|l|}
\hline Marker & ILS & SLS & ACT & SEM & ACC & ACH & Total & Percent \\
\hline -le & & & & & & 3 & 3 & $1.24 \%$ \\
\hline Modal & 16 & 3 & 27 & 1 & 20 & 41 & 108 & $44.63 \%$ \\
\hline Adverb & 12 & & 21 & & 11 & 28 & 72 & $29.75 \%$ \\
\hline Adv.+modal & 1 & & 2 & & & 2 & 5 & $2.07 \%$ \\
\hline LVM & 19 & & 11 & & 10 & 14 & 54 & $22.31 \%$ \\
\hline Total & 48 & 3 & 61 & 1 & 41 & 88 & 242 & $100 \%$ \\
\hline
\end{tabular}

Chinese does not mark tense grammatically. Future time references in Chinese are most frequently referred to by adverbs indicating futurity (e.g., jiang/yao "will, be going to") or by modals like hui "be likely to, be sure to", though it can also be lexicalized or implied in the context. When situations referred to by the English simple future are translated into Chinese, over three quarters of them take either adverbs indicating futurity and/or modals, while around one quarter take the LVM form. Future time reference and mood are so closely related that the question of whether the future (as in the case of English will) should be considered as tense or mood is an area of debate (c.f. Comrie, 1985: 21). As such, it is no surprise that future time reference is most frequently indicated by modals. Although the actual -le is not restricted to a certain time reference, our data shows that -le goes frequently with a past time reference (20.25\%) but rarely with a future time reference (1.24\%). This finding is in line with Comrie (1976) who argues that -le in Chinese signals both perfective aspect and tense meaning of relative past.

\section{Conclusion}

English has four viewpoint aspects: the progressive, the perfect, the perfect progressive and the simple. Our data show that around $88 \%$ of tensed verbs take the simple aspect. The perfect

\footnotetext{
${ }^{36}$ The count does not include incomplete structures like <s n="L1E_1525"> Probably it will, Dr. Brock replied and $<$ s n="L1E_1917"> But you'll always get that one who won't.
} 
accounts for roughly $8 \%$ while the progressive takes up $4 \%$. The perfect progressive is extremely rare (less than 0.5\%). Although both English and Chinese have a progressive aspect, the progressive has different scopes of meanings in the two languages. About $58 \%$ of situations referred to by the English progressive take the progressive or the durative aspect, either marked overtly or covertly in Chinese translations. The interaction between situation aspect and viewpoint aspect also influences the translator's choice of viewpoint aspect. Most telic situations (around $65 \%)$ and situations incompatible with progressiveness (92.5\% of ILSs and $75.9 \%$ of achievements) are more likely to undergo viewpoint aspect shift and presented perfectively. In contrast, atelic situations are normally translated with the progressive or the durative aspect ( $80 \%$ of SLSs and $87.2 \%$ of activities).

There are 4 types of perfect in English. The perfect of result, accounting for 59\% of all instances of perfect, goes only with telic situations. This type of perfect is most frequently (about 70\%) translated with the actual or the completive viewpoint in Chinese. The English perfect of experience and the experiential aspect in Chinese share the same meaning, therefore, translations of this type of perfect are rather straightforward. The perfect of persistent situation is typical of English and imperfective by nature. Translations of this type of perfect mainly take the LVM form, though there are variations because of the interaction between situation aspect and viewpoint aspect. Situations referred to by the English perfect of recent past are normally translated with the actual aspect in Chinese, because all situations in the recent past must be actualized and the focus is on their temporal nearness. The pluperfect (past perfect) refers to the "past in the past". As a situation with a past time reference must have been actualized, completed or mentally experienced, the pluperfect is most likely (90\%) to be presented with the actual, the experiential or the completive aspect in Chinese translations. When situations referred to by the English future perfect are translated into Chinese, the perfect meanings are lost and these situations are normally presented perfectively with a future time reference.

The perfect progressive is an interaction between the perfect and the progressive. Chinese translations of the perfect progressive may shift towards the progressive or the perfect meaning, depending on the situation type involved and the translator's choice of viewpoint. But in most 
cases both perfect and progressive meanings can be retained, with the perfect being lexicalized by temporal adverbs such as yizhi "all the time" while the progressive being signaled by the progressive aspect marker zai or implied by context. The pluperfect progressive is similar to the perfect progressive with the exception that it signals progressiveness with a relative past time reference. Situations referred to by the English pluperfect can be translated into Chinese with the progressive or the durative aspect unless the translator chooses to present them perfectively or there is a shift in situation type which prohibits them taking the progressive or the durative aspect.

The simple aspect in English presents a situation without aspectual modification. The simple past refers to a single situation completed or terminated in the past or a past habitual situation. More than $80 \%$ of the situations referred to by the English simple past are presented with a perfective viewpoint in Chinese translations. Past habitual situations referred to by the English simple past are not marked in Chinese translations. The simple present in English normally refers to states, namely, statements made "for all time" and habitual situations, though in highly specific circumstances, it can be used to mark a future or past situation or a situation in progress. When situations referred to by the English simple present are translated into Chinese, they are most likely (more than $80 \%$ ) to take the LVM form. Specifically, timeless situations are more likely to take the LVM form than other situations, and [-telic] situations are more likely to take the LVM form than [+telic] situations. The simple future refers to situations with a future time reference. When these situations are translated into Chinese, over three quarters of them take either adverbs indicating futurity (e.g. jiang "will, be going to" and/or modals (e.g., hui "be going to, be sure to"), while around one fourth take the LVM form.

In this paper, we explored, based on our English-Chinese parallel corpus, the translation patterns of English tense and aspect, which are undoubtedly beneficial to the construction of a language model for machine translation and machine-aided translation. In so doing, we have proved that parallel corpora are a useful resource for translation studies.

\section{References:}

1. Aarts, J (1998): Introduction, ed. Johansson \& Oksefjell Corpora and Cross-linguistic Research, Amsterdam-Atlanta, GA, 1998

2. Aijmer \& Altenberg (1996): Introduction, ed. Aijmer \& Altenberg Language in Contrast, 
Lund: Lund University Press

3. Baker, W (2002): English past simple \& present perfect in relation to Thai learners, Karen's Linguistic Issues, January 2002

Biber, D (1988): Variation across Speech and Writing, Cambridge University Press

4. Biber, D (1993): Representativeness in corpus design, Literary and Linguistic Computing, Vol.8, No. 4, 1993, pp243-257

5. Biber, D; Johansson, S; Leech, G; Conrad, S; Finegan, E (1999): Longman Grammar of Spoken and Written English, Longman

6. Boyland, J (1995): A corpus study of would+have+past-participle in English, XII International Conference on Historical Linguistics, Manchester, August 1995

7. Brinton, L (1988): The Development of English Aspectual System, Cambridge University Press

8. Bybee, J; Perkins, R; Pagliuca, W (1994): The Evolution of Grammar: Tense, Aspect and Modality in the Languages of the World, University of Chicago Press, 1994

9. Chao, Y (1968): A Grammar of Spoken Chinese, Berkeley: University of California Press

10. Christensen, M (1994): Variation in Spoken and Written Mandarin Narrative Discourse, unpublished $\mathrm{PhD}$ thesis, Ohio State University

11. Comrie, B (1976): Aspect, Cambridge: Cambridge University Press

12. Comrie, B (1985): Tense, Cambridge: Cambridge University Press

13. Dahl, O (1981): On the definition of the telic-atelic (bounded-unbounded) distinction, ed. Tedeschi \& Zaenen, Syntax and Semantics, (Vol. 14) Tense and Aspect, Academic Press, New York

14. Gao, M (1948): Hanyu Yufa Lun (Theory of Chinese Grammar), Commercial Publishing House

15. Gao, Z (1997): Automatic Extraction of Translation Equivalents from a Parallel Chinese-English Corpus, unpublished PhD thesis, University of Manchester

16. Garside, R (1990): The CLAWS word-tagging system, ed. Garside, Leech and Sampson, The Computational Analysis of English, Longman

17. Garside, R; Smith, N (1997): A hybrid grammatical tagger: CLAWS4, ed. Garside, Leech and McEnery, Corpus Annotation---Linguistic Information from Computer Text Corpora, pp102-121

18. Givon, T (1995): Functionalism and Grammar, John Benjamins Publishing Company

19. Gong, Q (1991):Tan xiandai hanyu de shizhi biaoshi he shitai biaoda xitong (On the system in modern Chinese to express tenses and aspects), Zhongguo Yuwen (Journal of Lingua, $04 / 91$

20. Henne, H et al (1977): A Handbook on Chinese Language Structure, Universitetsforlaget, Oslo

21. Hopper, P (1979): Aspect and foregrounding in discourse, ed. Givon, Discourse and Syntax

22. Johansson \& Hofland (1994): Towards an English-Norwegian parallel corpus, ed. Fries et, Creating and Using English Language Corpora, Rodopi, 1994

23. Leech, G (1971): Meaning and the English Verb, Longman

24. Lys, F; Mommer, K (1986): The problem of aspectual verb classification: a two-level approach, CLS (Chicago Linguistics Society) 22, part 2, pp 217-230

25. McEnery, A; Wilson, A (1996): Corpus Linguistics, Edinburgh University Press 
26. McEnery, A; Xiao, Z (2002): Domains, text types, aspect marking and English-Chinese translation, ICAME Conference 2002, Sweden, May 2002

27. Moens, M (1987): Tense, Aspect and Temporal Reference, unpublished $\mathrm{PhD}$ thesis, Edinburgh University, 1987

28. Mourelatos, A (1981): Events, processes, and states, ed. Tedeschi \& Zaenen, Syntax and Semantics, (Vol. 14) Tense and Aspect, Academic Press

29. Norman, J (1982): Chinese, Cambridge University Press, 1982

30. Park, B (2001): Introducing Korean National Corpus, Corpus Research Group, Lancaster University, Nov. $19^{\text {th }}$, 2001

31. Santos, D (1995): On the use of parallel texts in the comparison of languages, Actas do XI Encontro da Associação Portuguesa de Linguística (Lisboa, 2-4 de Outubro de 1995), pp.217-239

32. Santos, D (1996): Tense and Aspect in English and Portuguese: a Contrastive Semantical Study, unpublished PhD thesis, Universidade Tecnica de Lisboa, 1996

33. Smith, C (1997): The Parameter of Aspect, 2nd ed., Kluwer Academic Publishers

34. Svalberg, A; Chuchu, H. (1998): Are English and Malay worlds apart? International Journal of Applied Linguistics, 8/1: 27-60

35. Wang, L (1943): Zhongguo Xiandai Yufa (Modern Grammar of Chinese), Commercial Printing House, reprinted 1985

36. Weist, R.; Wysocka, H.; Witkowska-Stadnik, K.; Buczowska, E.; Konieczna, E. (1984): The defective tense hypothesis: on the emergence of tense and aspect in child Polish, Journal of Child Language, 11:347-374

37. Xiao, Z (2001): A corpus-based study of interaction between Chinese perfective -le and situation types, Proc. of Corpus Linguistics 2001 Conference 2001 Lancaster

38. Xiao, Z (2002): A Corpus-based Study of Aspect in Mandarin Chinese, unpublished $\mathrm{PhD}$ thesis, Lancaster University, 2002

39. Xiao, Z; McEnery, A (2002): A corpus-based two-level model of situation aspect, the $5^{\text {th }}$ Chronos Colloquium on Tense, Aspect and Modality, Groningen, the Netherlands

40. Zhang, L (1995): A Contrastive Study of Aspectuality in German, English \& Chinese, Berkeley insights in linguistics and Semiotics 19, Peter Lang

41. Zhou, Q; Yu, S (1997): Annotating the Contemporary Chinese Corpus, International Journal of Corpus Linguistics, 1997, Vol 2 No. 2 